Available online on 15.03.2020 at http://jddtonline.info
Open Access to Pharmaceutical and Medical Research
unrestricted non-commercial use, provided the original work is properly cited

Open 1 Access

Research Article

\title{
Formulation and Evaluation of Transdermal Topical Gel of Ibuprofen
}

\author{
Kashyap Ankita*, Das Asha, Ahmed Abdul Baquee \\ Girijananda Choudhury Institute of Pharmaceutical Science, Azara, Guwahati - 781017, Assam, India
}

\begin{abstract}
The present research work is based on the formulation and evaluation of topical gel of Ibuprofen where Carbopol 940 is used as the polymer. Gels were prepared by dispersing the polymers in a mixture of water and glycerol with methyl paraben as the preservative and the varying amount of ibuprofen, being kept under magnetic stirring until the homogeneous dispersion was formed. The dispersion was then neutralized and made viscous by the addition of triethanolamine. The Carbopol gels of Ibuprofen were found to be homogenous with good drug loading. The $\mathrm{pH}$ of all the gel formulations was found within the neutral pH range which is compatible with skin. And the viscosity of the formulations was found to be feasible for topical drug delivery. The drug content of the three formulations was found in the range of $87.56 \%$ to $90.45 \%$ which shows efficient drug loading. Results of In vitro drug release study showed that F5 formulation has better diffusion of drug through egg membrane and hence further permeation studies were carried out through rat epidermis. The compatibility study showed that the major peaks in FTIR spectra of the pure drug were found to be intact in their physical mixture. Hence there is no interaction between drug and Carbopol in their physical mixture. Carbopol can be effectively used as the polymer for topical gel preparation. And F5 formulation containing $0.5 \%$ w/w Carbopol 940 may be effectively used as topical transdermal delivery for Ibuprofen.
\end{abstract}

Keywords: Ibuprofen, Transdermal Gel, Drug release, Compatibility study

Article Info: Received 11 Jan 2019; Review Completed 14 Feb 2020; Accepted 20 Feb 2020; Available online 15 March 2020

Cite this article as:

Kashyap A, Das A, Ahmed AB, Formulation and Evaluation of Transdermal Topical Gel of Ibuprofen, Journal of Drug Delivery and Therapeutics. 2020; 10(2):20-25 http://dx.doi.org/10.22270/jddt.v10i2.3902

*Address for Correspondence:

Ankita Kashyap, Assistant Professor, Girijananda Choudhury Institute of Pharmaceutical Science, Azara, Guwahati-

781017, Assam, India

\section{INTRODUCTION}

The dosage forms, whether a tablet, an injection or a patch, to deliver the right amount of medicine at the right time to the right target site becomes complicated if each medicine is to be delivered in an optimal and preferred manner to the individual patient. The medication may not be absorbed if it is released too slowly or too rapidly, or the patient may suffer adverse effects and as because it's desired effects may not last as long as it needed. These limitations are being overcome by transdermal drug delivery systems as they achieve several advantages over conventional dosage forms. Transdermal drug delivery is a route which can deliver medicines via the skin portal to systemic circulation at a predetermined rate and maintain clinically effective concentrations over a prolonged period of time. Transdermal route of drug administration avoids discomfort associated with parental therapy and improves patient compliance. This route of administration also eliminates the side effects that are caused by the conventional drug forms and also provide controlled release of drugs directly into the bloodstream through the intact skin. Transdermal delivery can provide a number of advantages over the conventional method of drug administration like-enhanced efficacy, increased safety, greater convenience, improved patient compliance. The various advantages of Transdermal Drug Delivery System are - It avoids significant presystemic metabolism and therefore the need for the daily requirement is low. It reduces inter and intrapatient variability. Drug levels can be maintained in the systemic circulation within the therapeutic limit. The duration of drug action following a single administration of the drug can be extended and the frequency of dosing is reduced. It improves patient compliance and acceptability of the drug therapy. Drug input can be terminated simply by removal of the patch.[1,2,3] Taking into account several advantages associated with Transdermal drug delivery route, we have decided to utilize 'Ibuprofen', which is a nonsteroidal anti-inflammatory drug (NSAID) used for pain relief, fever reduction, and against swelling.[4] Carbopol 940 is used as the polymer, which is ideal for applications such as clear gels, hydroalcoholic gels, creams. [5,6] 


\section{Objective}

The objective is to prepare transdermal topical gel of Ibuprofen using Carbopol 940 which can be effectively used for transdermal topical delivery.

\section{MATERIALS AND METHODS}

\section{Materials}

Chemicals

Ibuprofen (Hi Media, Mumbai, India), Triethanolamine (Merck ,Mumbai, India), Methyl Paraben (Hi Media, Mumbai, India), Glycerol (Merck, Mumbai, India), Carbopol (Balaji Drugs, India) were procured and used in the investigation.All other reagents used were of analytical grade.

\section{Animals}

Wistar albino rats (male) were used of 250-500 gm were used which were supplied by animal house of Girijananda Chowdhury Institute of Pharmaceutical Science which were kept under proper laboratory condition. The animals were received only after the proposed study was approved by the Institute Animal Ethics committee bearing the number GIPS/IAEC/BPH/2013/4.

\section{Preparation of standard curve:}

$0.1 \mathrm{mg}$ of ibuprofen was weighed accurately and was dissolved in $10 \mathrm{ml}$ of ethanol and the volume was adjusted to $100 \mathrm{ml}$ by $\mathrm{pH} 7.4$ and various dilutions were made to obtain concentration 2-50 $\mathrm{mcg} / \mathrm{ml}$ and the absorbance was measured in the Ultra Violet (UV) Spectrophotometer at $\lambda \max 267 \mathrm{~nm}$, and a standard curve was obtained by plotting concentration against the absorbance.[7]

\section{Preparation of transdermal gel:}

Gels were prepared by dispersing the polymers (Carbopol 940 ) in a mixture of water and glycerol with methylparaben as the preservative and the varying amount of ibuprofen, being kept under magnetic stirring until the homogeneous dispersion was formed. The dispersion was then neutralized and made viscous by the addition of triethanolamine $[8,9]$ as shown in Table 1.

Table 1: Gel Formulation

\begin{tabular}{|c|c|c|c|c|c|}
\hline $\begin{array}{c}\text { Formulation } \\
\text { Code }\end{array}$ & Drug (mg) & $\begin{array}{c}\text { Carbopol 940 } \\
\text { (gm) }\end{array}$ & $\begin{array}{c}\text { Methyl Paraben } \\
\text { (mg) }\end{array}$ & Glycerin (ml) & $\begin{array}{c}\text { Triethanolamine } \\
\text { (ml) }\end{array}$ \\
\hline F1 & 10 & 1 & 200 & 1 & 0.1 \\
\hline F2 & 10 & 0.5 & 200 & 1 & 0.1 \\
\hline F3 & 10 & 0.75 & 200 & 1 & 0.1 \\
\hline F4 & 20 & 0.5 & 200 & 1 & 0.1 \\
\hline F5 & 50 & 0.5 & 200 & 1 & 0.1 \\
\hline
\end{tabular}

\section{Preparation of $\mathrm{pH}$ 7.4:}

2.38 gm of Disodium Hydrogen Phosphate, $0.19 \mathrm{gm}$ of Potassium Dihydrogen Phosphate and $8 \mathrm{gm}$ of Sodium Chloride were weighed accurately and it was diluted up to $1000 \mathrm{ml} .[10]$

\section{Evaluation Of Transdermal Gel:}

\section{Determination of gel $\mathrm{pH}$}

The $\mathrm{pH}$ of the three gel formulations was determined by using digital $\mathrm{pH}$ meter after calibration with standard buffer $\mathrm{pH} 4.0$, and 9.0 by inserting the electrode system into the gel.[11]

\section{Spreadability}

One of the criteria for a gel to meet the ideal quantities is that it should possess good spreadability. It is the term expressed to denote the extent of the area to which gel readily spreads on application to the skin or affected part. The therapeutic efficacy of a formulation also depends upon its spreading value. Spreadability is expressed in terms of time in seconds taken by two slides to slip off from the gel and placed in between the slides under the direction of certain load. Lesser the time is taken for separation of two slides, better the spreadability. It is calculated by using the formula: $\mathrm{S}=\mathrm{M}$. L / T Where $\mathrm{M}=$ weight tied to upper slide, $\mathrm{L}$ = length of the glass slide, $\mathrm{T}=$ time taken to separate the slides.[12]

\section{Viscosity}

Brookfield (DV-E Viscometer) attached with spindle was used for determination of viscosity. Gels were filled in jar and spindle was lowered perpendicularly taking care that spindle does not touch the bottom of the jar. The spindle number 63 was rotated in the gel at $20 \mathrm{rpm}$. At each speed, the corresponding dial reading was noted. The reverse reading was also noted and average was taken for these two readings. The viscosity of the gel was obtained by the multiplication of the dial readings with the factors given in the Brookfield viscometer catalogs. The spindle size used is 64.[13]

\section{Drug content}

$1 \mathrm{gm}$ of the prepared gel was weighed accurately and dissolved in $10 \mathrm{ml}$ of ethanol and was then filtered.1ml of the filtrate was taken and was diluted up to $100 \mathrm{ml} \mathrm{by} \mathrm{pH} 7.4$ and was observed in the Ultra violet (UV) spectrophotometer at $267 \mathrm{~nm} .[14,15,16]$

\section{In-vitro drug release/permeation study}

The drug release/ permeation studies of the prepared gels were carried out in Keshary-Chien diffusion cell for studying the drug release from the gels through an egg membrane. Gel sample $(0.5 \mathrm{~g})$ was placed on the membrane and the diffusion studies were carried out at $37 \pm 0.5^{\circ} \mathrm{C}$ using $250 \mathrm{ml}$ of phosphate buffer ( $\mathrm{pH}$ 7.4) as the receptor medium. Five milliliters of each sample was withdrawn periodically at 15 , CODEN (USA): JDDTAO 
30, 60, 120 and 240 minutes. Each sample was replaced with equal volume of fresh receptor medium. Then the samples were analyzed by UV spectrophotometer at $267 \mathrm{~nm}$ for the drug content by using phosphate buffer as blank.[17,18,19]

\section{Compatibility study}

The Fourier- transform infrared spectroscopy (FTIR) spectra of pure drug, Carbopol, and physical mixture of drug Carbopol (1:3) were taken and studied for any interaction using FTIR, Bruker Alpha instrument.[20,21,22]

\section{RESULT AND DISCUSSION}

\section{Standard calibration curve of Ibuprofen:}

The standard calibration curve of Ibuprofen was plotted in phosphate buffer, $\mathrm{pH}$ 7.4. The scanning of standard solution has resulted maximum absorption peak at the wavelength of $267 \mathrm{~nm}$. It was observed that Beer-Lambert's law was obeyed within the concentration range of $2.0 \mu \mathrm{g} / \mathrm{ml}$ to 50.0 $\mu \mathrm{g} / \mathrm{ml}$, in phosphate buffer, $\mathrm{pH} 7.4$ as shown in Table 2 and Fig. 1.

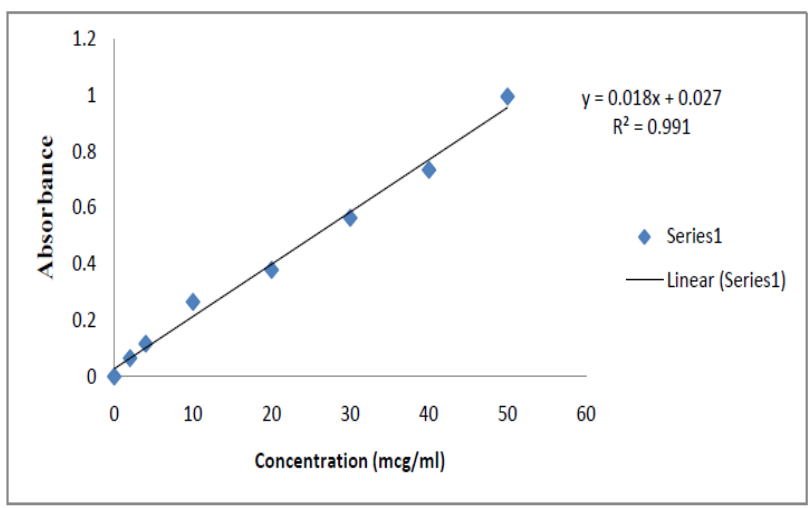

Fig 1: Standard Curve of Ibuprofen

\section{$\mathrm{PH}^{\mathrm{H}}$ of Ibuprofen Gel:}

The $\mathrm{pH}$ of the gel formulations was found as 7.0 to 7.5 and a comparison study was done with a standard gel as shown in Table 2.

Table 2: pH of Gel Formulation

\begin{tabular}{|c|c|}
\hline Formulation & $\mathrm{pH}($ mean \pm SD $)$ \\
\hline F1 & $7.2 \pm 0.18$ \\
\hline F2 & $7.5 \pm 0.20$ \\
\hline F3 & $7.0 \pm 0.15$ \\
\hline F4 & $7.3 \pm 0.07$ \\
\hline F5 & $7.2 \pm 0.18$ \\
\hline Nurofen (Boots Healthcare) & $7.4 \pm 0.14$ \\
\hline
\end{tabular}

\section{Drug spreadability study:}

The spreadability of the different gel formulations after 1 min. was determined and was compared with a standard gel and noted in Table 3.

Table 3: Spreadability of Gel Formulation

\begin{tabular}{|c|c|}
\hline Formulation & Spreadibility (mean \pm SD) \\
\hline F1 & 19.79 \\
\hline F2 & 22.5 \\
\hline F3 & 21.25 \\
\hline F4 & 22.29 \\
\hline F5 & 22.08 \\
\hline Nurofen (Boots Healthcare) & 21 \\
\hline
\end{tabular}

\section{Viscosity:}

The viscosity of the gel formulations was found between 15900 to $23230 \mathrm{cps}$. The results are shown in Table 4 .

Table 4: Viscosity of Gel Formulation (20 rpm)

\begin{tabular}{|c|c|}
\hline Formulation & Viscosity (mean \pm SD) \\
\hline F1 & $20800 \pm 4336.828$ \\
\hline F2 & $23230 \pm 4984.532$ \\
\hline F3 & $27700 \pm 5981.081$ \\
\hline F4 & $15900 \pm 2969.848$ \\
\hline F5 & $20100 \pm 4984.532$ \\
\hline
\end{tabular}

\section{Drug Content:}

The drug content of the gel formulations was found in the range of 87.56 to $90.45 \%$ which shows efficient drug loading. The results are shown in Table-5.

Table 5: Drug Content of Different Formulation

\begin{tabular}{|c|c|}
\hline Formulation & Drug Content (mean \pm SD) \\
\hline F1 & $87.56 \pm 1.11$ \\
\hline F2 & $89.67 \pm 0.85$ \\
\hline F3 & $88.44 \pm 1.02$ \\
\hline F4 & $90.45 \pm 0.94$ \\
\hline F5 & $89.12 \pm 0.85$ \\
\hline
\end{tabular}

\section{In-vitro drug release/permeation study:}

In-vitro drug release of all the formulation through egg membrane is shown in Fig-2. 


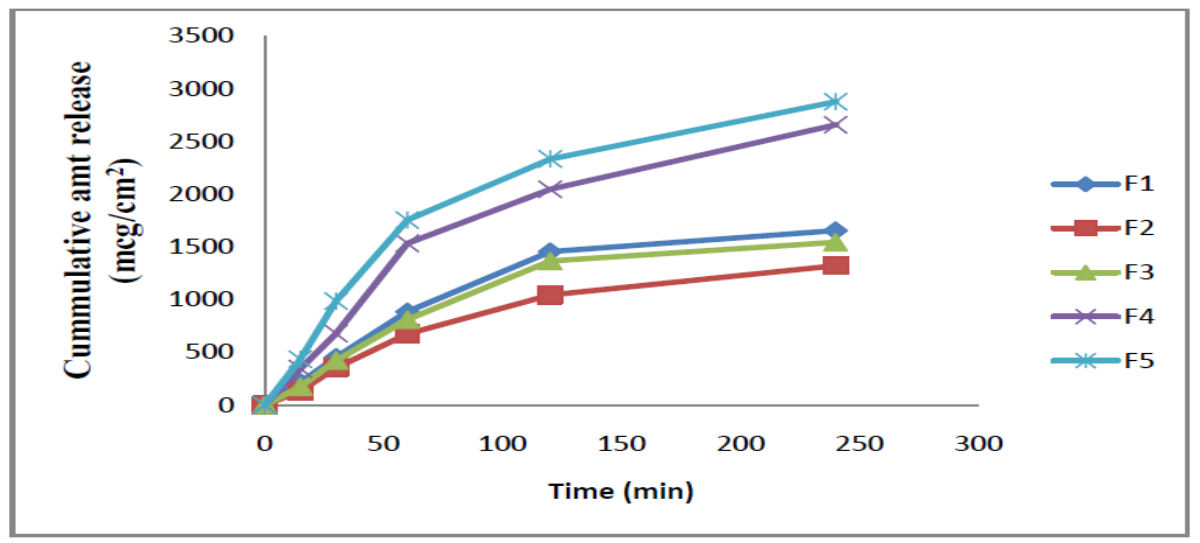

Fig 2: RELEASE PROFILE OF IBUPROFEN FROM GELS THROUGH EGG MEMBRANE Formulation F5 shows the highest release across the egg membrane chosen for permeation across rat epidermis. The result of permeation of transdermal gel across rat epidermis is shown in Fig 3.

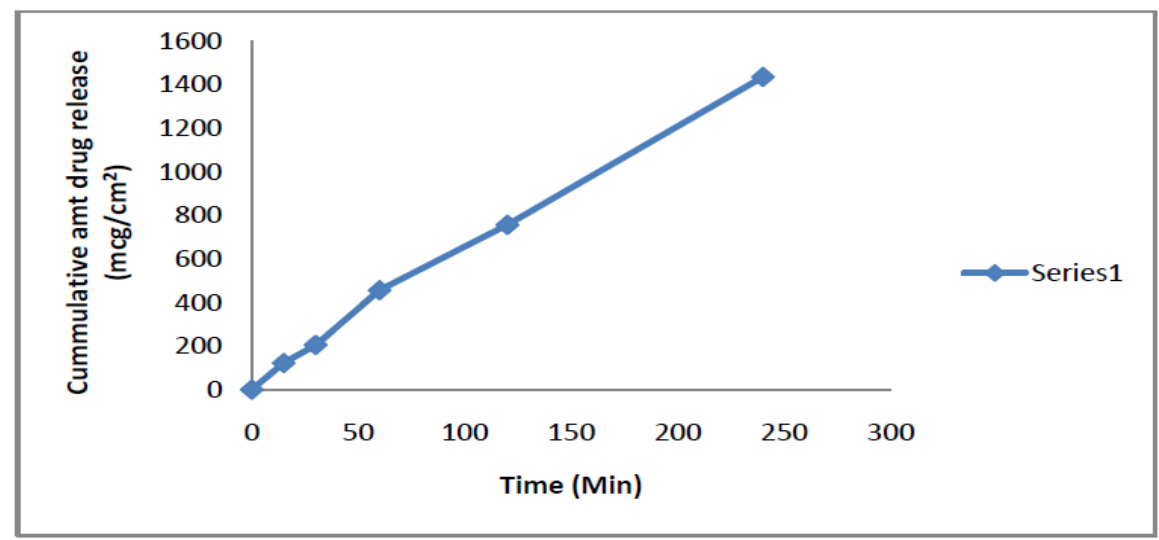

Fig 3: Permeation Profile oF Ibuprofen from Transdermal Gel through Rat Epidermis

\section{Drug compatibility study:}

Fourier- transform infrared spectroscopy (FTIR) spectra of pure drug, carbopol 940 and 1:3 ratio of the physical mixture of drug- carbopol 940 is presented in Fig-7 to 9 respectively. All the major peaks such as of alkenes i.e. C-H (stretching) at 2988.29, 2949.21, 2867.97, carbonyl group i.e. $\mathrm{C}=0$ (stretching) at 1707.22, aromatic $\mathrm{C}=\mathrm{C}$ (stretching) at 1504.04, alkyl halide groups i.e. $\mathrm{C}=\mathrm{F}$ (stretching) at 1454.85 , 1266.87, 1225.51, 1179.08, are retained in the physical mixture. Thus it indicates that the drug is compatible with the polymer used in the formulations as shown in Fig.4, Fig.5, Fig.6.

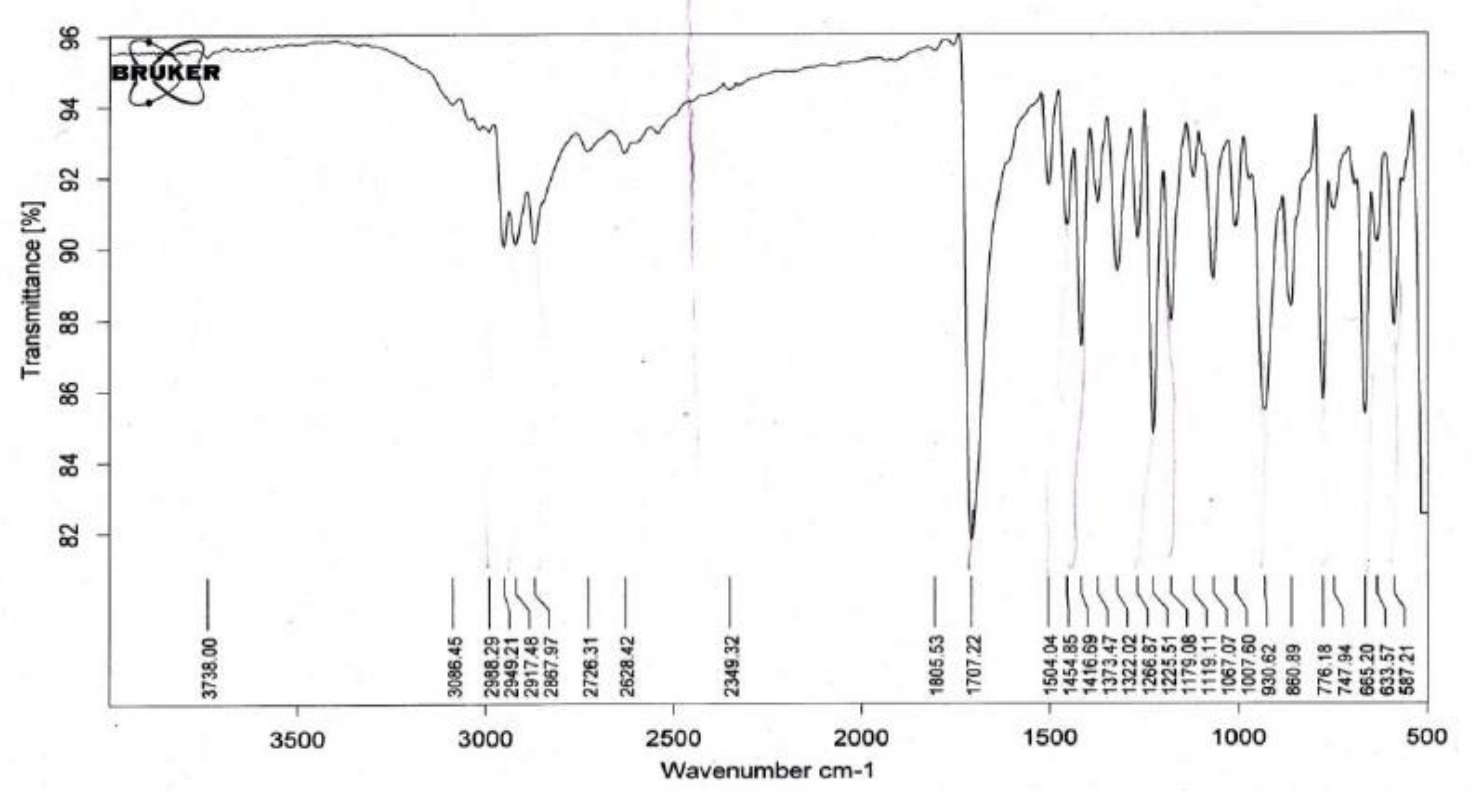

Fig-4: FTIR Spectra of Pure Drug (Ibuprofen) 


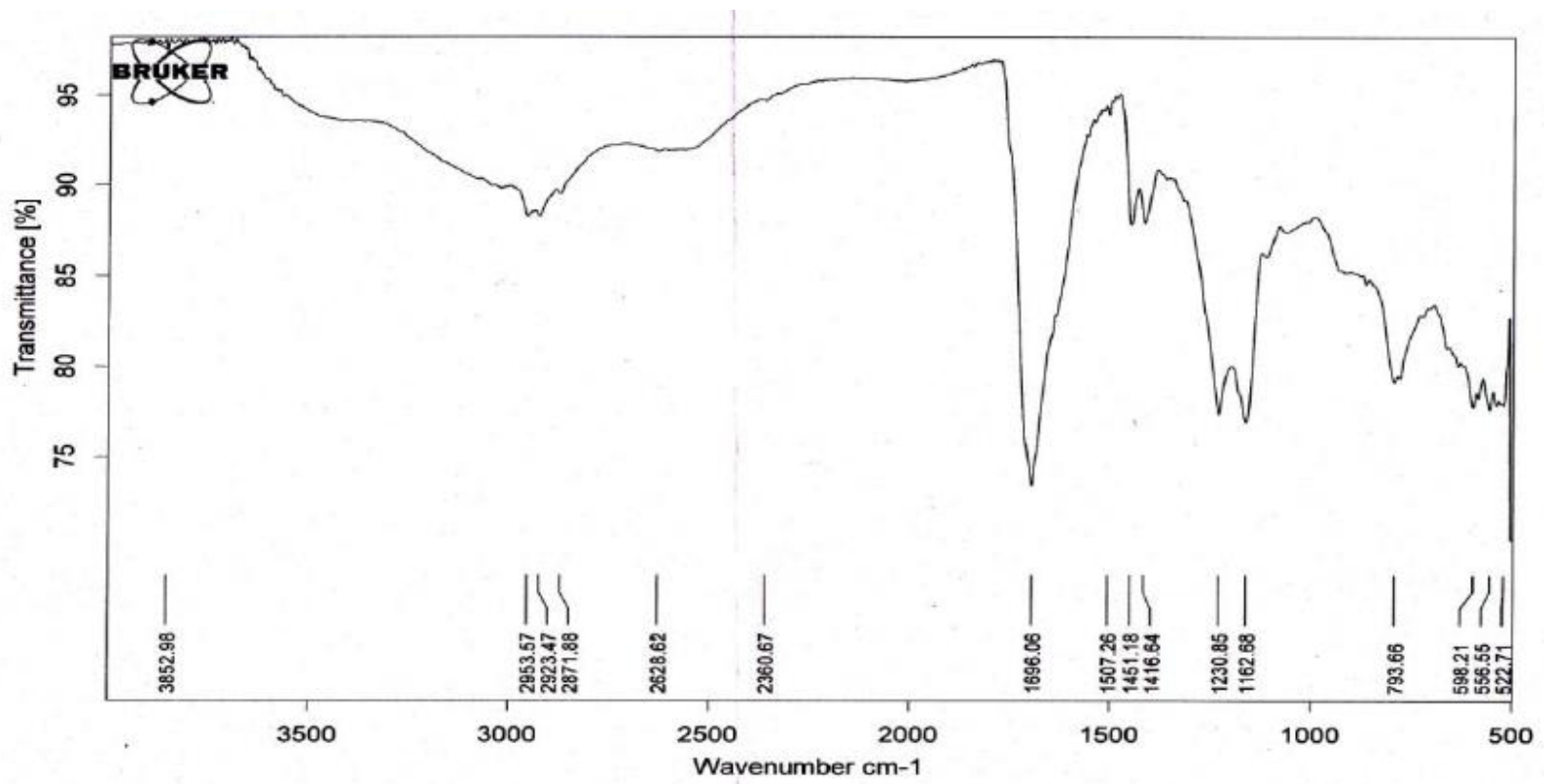

Fig-5: FTIR Spectra of Carbopol 940

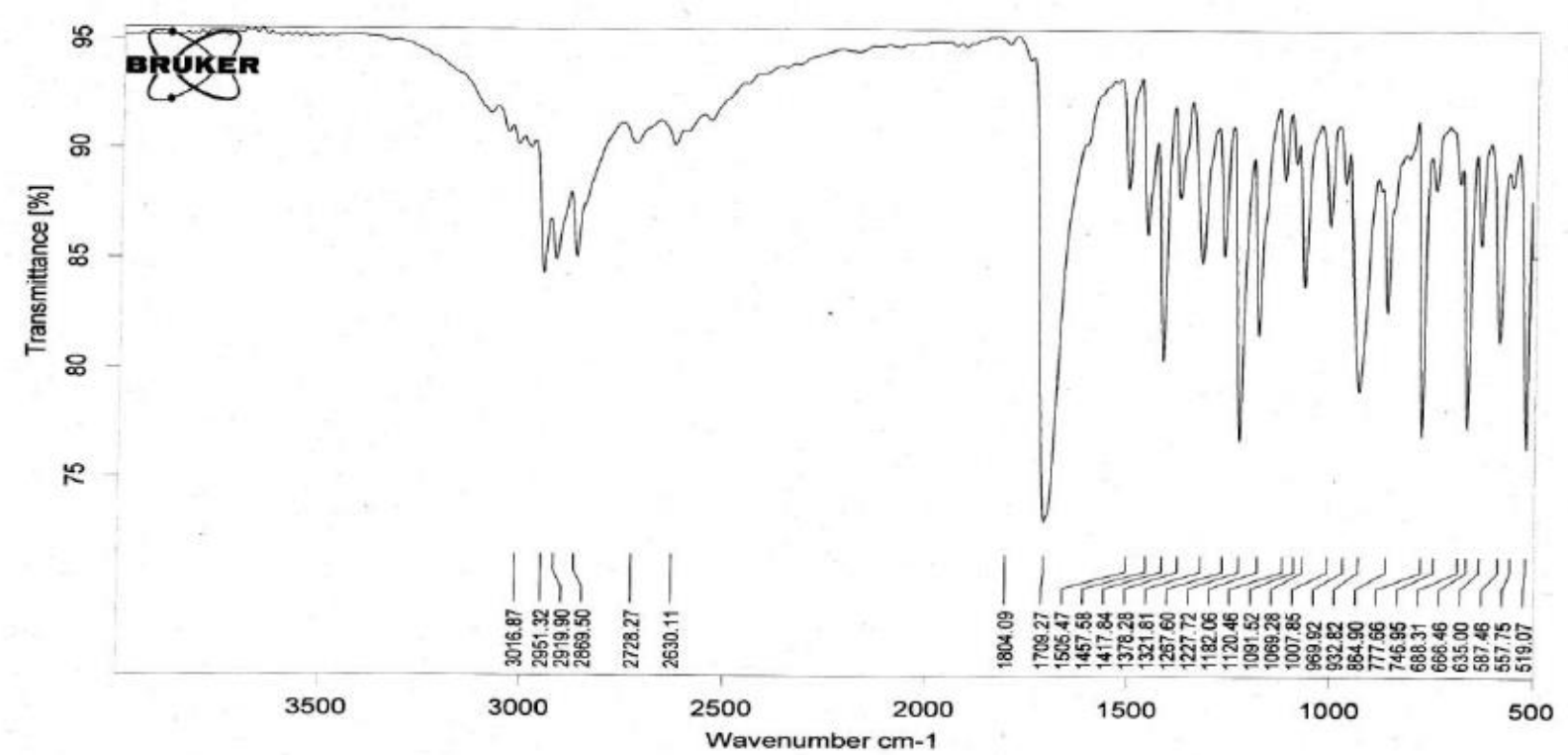

Fig-6: FTIR Spectra of Ibuprofen:Carbopol 940

\section{DISCUSSION}

The Carbopol gels of Ibuprofen were found to be homogenous with good drug loading. The $\mathrm{pH}$ of all the gel formulations was found within the neutral $\mathrm{pH}$ range which is compatible with skin. And the viscosity of all formulations was found to be feasible for topical drug delivery. The drug content of the three formulations was found in the range of 87.56 to $90.45 \%$ which shows efficient drug loading. Results of in-vitro drug release study showed that F5 formulation has better diffusion of drug through egg membrane and hence further permeation studies were carried out through rat epidermis. The compatibility study showed that the major peaks in Fourier- transform infrared spectroscopy (FTIR) spectra of the pure drug were found to be intact in their physical mixture. Hence there is no interaction between drug and Carbopol in their physical mixture.

\section{CONCLUSION}

It can be concluded that Carbopol can be effectively used as the polymer for topical gel preparation. And F5 formulation containing $0.5 \%$ w/w Carbopol 940 may be effectively used as topical transdermal delivery for Ibuprofen.

\section{ACKNOWLEDGMENT}

I am sincerely thankful to Girijananda Choudhury Institute of Pharmaceutical Science, Guwahati for carrying out the study and also grateful to my colleagues for their helping hand support and coordination. 


\section{REFERENCES}

1. Vyas PS, Khar KR, "Drug delivery system”, 2012; 2: 397-399.

2. Robinso JR, Lee HL, "Controlled drug delivery fundamentals and applications”, 1987; 2: 524-552.

3. Aqui SY, Ali A, "Matrix type transdermal drug delivery systems of metoprolol tartrate: In vitro characterization" Acta Pharm, 2003; 119-125.

4. Baselt R, "Disposition of toxic drugs and chemicals in Man,Foster city" Biomedical Publications, 2008; 8: 758-761.

5. Misra AN, "Controlled and novel drug delivery" CBS Publishers and Distributors, 1997; 107-109.

6. Singh J, Tripathi KP and Sakia TR, "Effect of penetration enhancers on the in vitro transport of ephedrine through rat skin and human epidermis from matrix based transdermal formulations" Drug Dev Ind Pharm, 1993;1623-1628.

7. Farra H, Letzig L, Gil M, "Validation of a liquid chromatographic method for the determination of ibuprofen in human plasma" Journal of Chromatography, 2002; 780: 341-348.

8. Barkin RL, "Topical Nonsteroidal Anti-Inflammatory Drugs: The Importance of Drug, Delivery, and Therapeutic Outcome" American Journal of Therapeutics, 2015; 22:388-407.

9. Dantas MGB, Reis SA, Damasceno CMD, Rolim LA, Rolim-Neto PJ, Carvalho, FO, Quintans-Junior LJ and Silva JR "Development and Evaluation of Stability of a Gel Formulation Containing the Monoterpene Borneol" The Scientific World Journal, 2016

10. Patel H, Panchal M, Shah S and Vadalia KR, "Formulation and Evaluation of Transdermal Gel of Sildenafil Citrate" International Journal of Pharmaceutical Research \& Allied Sciences, 2012;1:103-118.

11. Ahme SZ, Nahid K, Alaadin A, Mark S, Sarah I, Rahman Z,Cruz C and Muhammad A, "Effect of Isopropyl Myristate on Transdermal Permeation of Testosterone from Carbopol Gel" Journal of Pharmaceutical Sciences, 2017.

12. Marwa HS, Ghada FM, "Evaluation of Topical Gel Bases Formulated with Various Essential Oils for Antibacterial Activity against Methicillin Resistant Staphylococcus Aureus" Tropical Journal of Pharmaceutical Research, 2013;12: 877884.
13. Ujwala A, Modani SH and Singh KH, "Design and Development of Repaglinide Microemulsion Gel for Transdermal Delivery" AAPS PharmSciTech, 2018.

14. Mohamed A, Amira AM, Mohammed AA and Abdulrhman AO, "An in vivo study of Hypericum perforatum in a niosomal topical drug delivery system" Drug Delivery, 2018; 25: 417425.

15. Jangdey MS, Gupta A and Saraf S: Fabrication, "In-vitro characterization, and enhanced in-vivo evaluation of carbopolbased nanoemulsion gel of apigenin for UV-induced skin carcinoma" Drug Delivery, 2017; 24:1026-1036.

16. Ali DF, Ahmed AA, Hamza MY and Mohamed MI "Microemulsion for Topical Delivery of Fenoprofen Calcium: In-vitro and In-vivo Evaluation Journal of Liposome Research", 2017; 1532-2394.

17. Pawar J, Narkhede R, Amin, P and Tawde V, 'Design and Evaluation of Topical Diclofenac Sodium Gel Using Hot Melt Extrusion Technology as a Continuous Manufacturing Process" AAPS Pharm SciTech, 2017; 5:1530-9932.

18. Kalita B, Das MK, Sarma M and Deka A, "Sustained Antiinflammatory Effect of Resveratrol-Phospholipid Complex Embedded Polymeric Patch" AAPS PharmSciTech, 2016.

19. Okur NU, Caglar E, Muhammet DA and Karasulu YK, "Preparation and evaluation of novel microemulsion-based hydrogels for dermal delivery of benzocaine" Pharmaceutical Development and Technology, 2017; 22: 500-510.

20. Nanda S, Saroha K and Sharma B, "Formulation, Evaluation And Optimization of Transdermal Gel Of Ketorolac Tromethamine Using Face Centred Central Composite Design" International Journal of Pharmacy and Pharmaceutical Sciences, 2014; 6:0975-1491.

21. Ahmed MG, "Formulation and Evaluation Of Transdermal Gel Of Lornoxicam In Combination With Chemical Enhancers" International Journal of Research In Pharmacy and Chemistry, 2014; 4:996-1003.

22. Acharya A, Dhakal P, and Khadka D, "Formulation and Evaluation of Transdermal Gel of Lornoxicam and its Delivery by Passive and Inotophoresis Method: A Comparative Study" International Journal of Pharmaceutical Sciences and Research, 2017. 